\title{
latrogenic Influences on the Heritability of Childhood Tonsillectomy: Cohort Differences in Twin Concordance
}

\author{
N.G. Martin', U. Kehren', D. Battistutta', J.D. Mathews ${ }^{2}$ \\ ${ }^{1}$ Queensland Institute of Medical Research, Bramston Terrace, Brisbane, ${ }^{2}$ Menzies School of \\ Health Research, Darwin, Australia.
}

\begin{abstract}
In 1980-82, a mailed questionnaire was completed by 3,810 pairs of adult twins enrolled on the Australian NH\&MRC Twin Register. Twins were asked whether they had had their tonsils out and, if so, at what age. The sample was divided into four birth cohorts of approximately equal size, and only childhood tonsillectomy (to the age of 18) was considered. The prevalence of tonsillectomy differed markedly between cohorts, being highest in those born in the 1940s and early 1950s. Within each cohort, the prevalence was very similar in $\mathrm{MZ}$ and $\mathrm{DZ}$ twins, yet concordance was much higher in MZ twins, indicating the importance of genetic factors in predisposition to tonsillectomy. However, the proportions of variance in liability due to genetic and shared environmental factors differed markedly between cohorts. In the 1950 s, when tonsillectomy was fashionable, shared environment accounted for $60 \%$ of variance and genetic factors for only $29 \%$. However, by the early 1960 s, when tonsillectomy was going out of fashion, heritability was up to 0.82 and shared environment accounted for only $10 \%$ of variance. Our results illustrate, once again, that heritability is not a constant, but depends on the precise characteristics of the population and the time at which it is studied.
\end{abstract}

Key words: Tonsillectomy, Heritability, Iatrogenesis, Cohort effects, Twins

\section{INTRODUCTION}

Tonsillectomy is one of the most common surgical procedures in developed countries, although its popularity has waned in recent years with doubts about its efficacy and increasing availability of antibiotics $[5,11,15]$. The primary indication for tonsillectomy is recurrent attacks of tonsillitis [10]. The frequency and severity of these attacks is de- 
termined in part by immunological factors [13] which are known to be genetically influenced [2]. Thus, there are a priori reasons for supposing that genetic factors may be involved in the risk of tonsillectomy. But given the striking swings in popularity of the operation, we might expect the beliefs of parents and the family doctor to modify the influence of any genetic factors. We have investigated the importance of genetic variation in liability to tonsillectomy and the extent to which it is modified by family and social environment.

\section{SUBJECTS AND DATA}

In 1980-82, a questionnaire was mailed to all 5,967 adult ( $\geq 18 \mathrm{yr}$ ) pairs enrolled on the Australian NH\&MRC Twin Register. Replies were received from 3,810 complete pairs, a $64 \%$ pairwise response rate. Enrollment on the Register and return of the questionnaire were both voluntary but the twins were otherwise unselected. Twins were asked whether they had had their tonsils out and, if so, at what age. There were 3,135 individuals $(41 \%)$ who indicated that they had had a tonsillectomy, at a median age of about 7 years. For subsequent analysis, the sample was divided into four birth cohorts of approximately equal size - those born before 1939, in 1939-1950, 1951-1958, and 1959 1964. The age distribution and its division into the four cohorts are shown in Fig. 1.

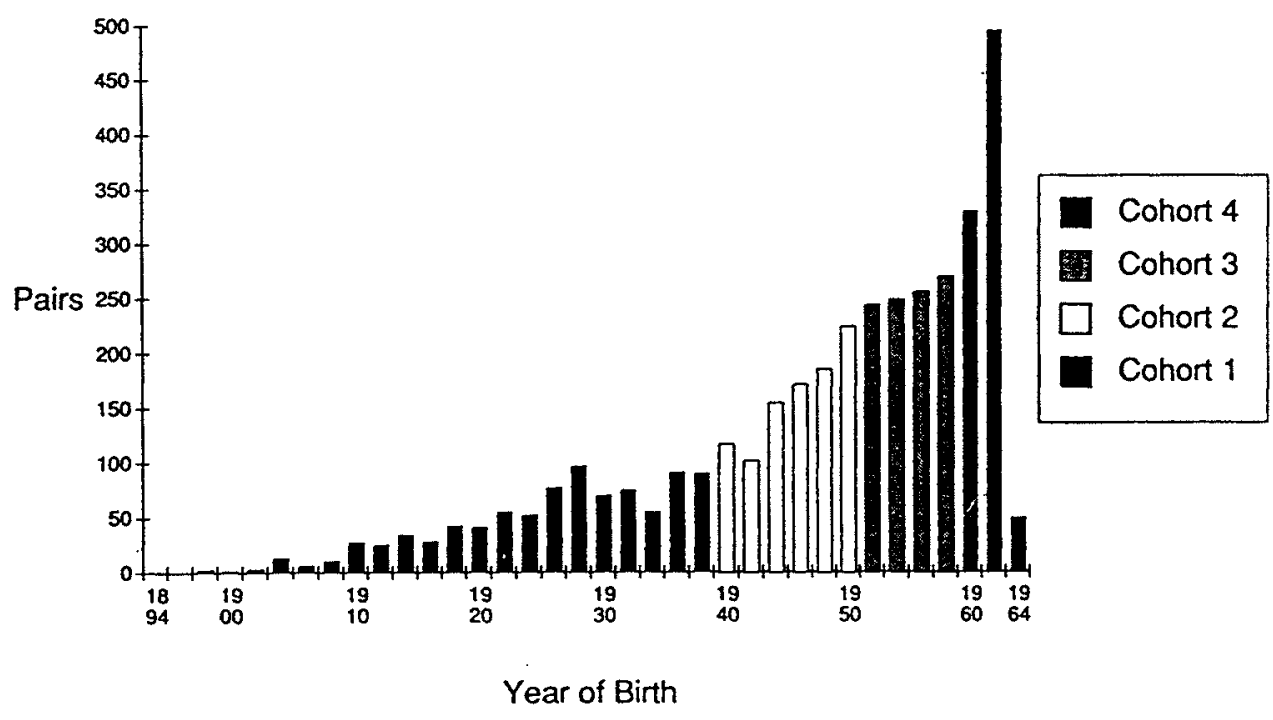

Fig. 1. Cohort structure of the twin sample.

To ensure comparability between cohorts, only tonsillectomy to age 18 was considered, those who reported having the operation after the age of 18 ( 365 individuals) being recoded as negative. Those who did not give the age at which their tonsillectomy was performed were excluded from the analysis and 130 pairs were discarded for this reason. 


\section{ANALYSIS}

Considerable heterogeneity in survival to tonsillectomy was found between cohorts $\left(\chi_{3}^{2}=135\right.$, Fig. 2) but there was no heterogeneity between sexes within cohorts, nor between first- and second-born twins. Between $\mathrm{MZ}$ and $\mathrm{DZ}$ twins of the same sex, slight heterogeneity $(P=0.04)$ was observed in females of the pre-1939 birth cohort, in which $270 \mathrm{MZ}$ individuals $(41 \%)$ vs $135 \mathrm{DZ}$ females (35\%) reported tonsillectomy; heterogeneity was also found in males of the $1959-64$ cohort $(P=0.03)$, in which $66 \mathrm{MZ}$ males $(28 \%)$ vs $39 \mathrm{DZ}$ individuals $(19 \%)$ had their tonsils out. It can be seen that childhood tonsillectomy was most popular in the $1939-50$ birth cohort and has been declining since then.

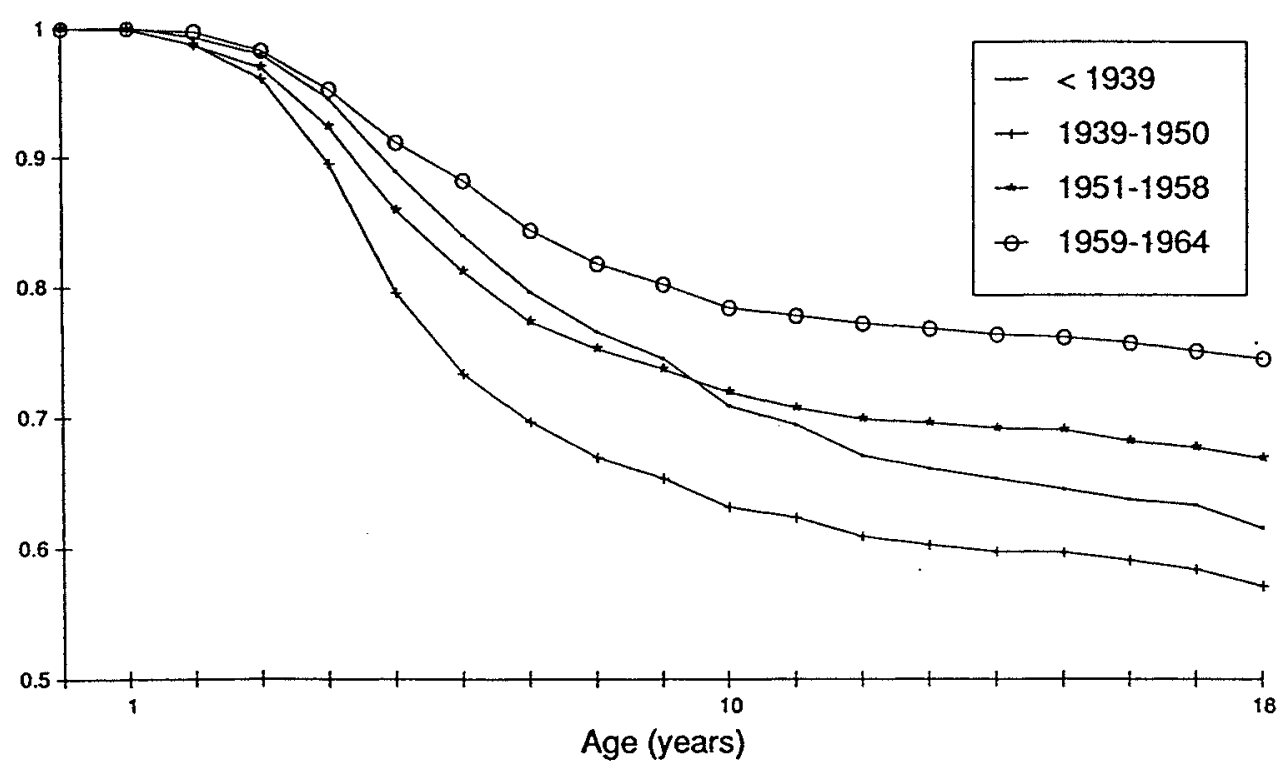

Fig. 2. Survival to age at tonsillectomy (to age $\leq 18$ ) by cohort.

What is the effect of this change of surgical fashion on the concordance for tonsillectomy in twins? We assume a latent normal distribution of liability which determines the risk of tonsillectomy and that the joint distribution of liabilities for a pair of twins is bivariate normal [4]. Twin correlations in liability are estimated as tetrachoric correlations from $2 \times 2$ contingency tables for each twin group using the computer program PRELIS [8]. Contingency tables are shown in Table 1 and tetrachoric correlations and their asymptotic standard errors in Table 2 and graphically in Fig. 3. It can be seen that $\mathrm{MZ}$ correlations are fairly constant for all cohorts but that $\mathrm{DZ}$ correlations increase to a maximum in the 1951-58 cohort and then fall sharply in the youngest group.

Putative influences on liability to tonsillectomy in a pair of twin are: additive genetic factors which influence liability to the extent $h$, common or shared environmental in- 
Table 1 - Concordance in twin pairs for tonsillectomy by zygosity, sex and cohort. Individuals who have had a tonsillectomy before age 19 are classified as "Yes" ( $Y$ ), those who have not as "No" (N)

\begin{tabular}{|c|c|c|c|c|c|c|c|c|c|c|c|c|c|c|c|c|c|c|c|c|}
\hline \multirow{2}{*}{ Cohort } & \multicolumn{4}{|c|}{$\mathrm{MZ}$ females } & \multicolumn{4}{|c|}{$\mathrm{MZ}$ males } & \multicolumn{4}{|c|}{$\mathrm{DZ}$ females } & \multicolumn{4}{|c|}{$\mathrm{DZ}$ males } & \multicolumn{4}{|c|}{ DZ opposite-sex } \\
\hline & NN & NY & YN & $Y Y$ & $\mathrm{NN}$ & NY & YN & YY & NN & NY & YN & YY & NN & NY & $Y N$ & $Y Y$ & NN & NY & YN & $Y Y$ \\
\hline 1 & 170 & 25 & 27 & 109 & 67 & 13 & 10 & 37 & 99 & 29 & 26 & 40 & 36 & 6 & 14 & 11 & 90 & 31 & 20 & 41 \\
\hline 2 & 158 & 21 & 27 & 104 & 80 & 13 & 6 & 57 & 83 & 37 & 20 & 58 & 32 & 14 & 7 & 16 & 87 & 22 & 23 & 61 \\
\hline 3 & 183 & 23 & 26 & 88 & 84 & 7 & 9 & 39 & 111 & 16 & 21 & 40 & 54 & 8 & 12 & 24 & 147 & 20 & 33 & 45 \\
\hline 4 & 167 & 11 & 14 & 48 & 81 & 3 & 7 & 28 & 96 & 24 & 14 & 18 & 72 & 9 & 14 & 8 & 149 & 32 & 34 & 34 \\
\hline
\end{tabular}

Table 2 - Tetrachoric correlations and standards errors for liability to tonsillectomy to age 18 by zygosity, sex and cohort

\begin{tabular}{|c|c|c|c|c|c|c|c|c|c|c|c|c|}
\hline & \multicolumn{3}{|c|}{$\begin{array}{c}\text { Cohort } 1 \\
\text { Born }<1939\end{array}$} & \multicolumn{3}{|c|}{$\begin{array}{c}\text { Cohort } 2 \\
\text { Born } 1939-1950\end{array}$} & \multicolumn{3}{|c|}{$\begin{array}{c}\text { Cohort } 3 \\
\text { Born 1951-1959 }\end{array}$} & \multicolumn{3}{|c|}{$\begin{array}{c}\text { Cohort } 4 \\
\text { Born 1959-1964 }\end{array}$} \\
\hline & $\mathrm{N}$ & $r$ & se & $\mathrm{N}$ & $r$ & $\mathrm{se}$ & $\mathrm{N}$ & $r$ & $\overline{\text { se }}$ & $\bar{N}$ & $r$ & se \\
\hline $\mathrm{MZF}$ & 331 & 0.87 & 0.03 & 310 & 0.88 & 0.03 & 320 & 0.87 & 0.03 & 240 & 0.92 & 0.03 \\
\hline MZM & 127 & 0.83 & 0.06 & 156 & 0.93 & 0.03 & 139 & 0.92 & 0.04 & 119 & 0.96 & 0.03 \\
\hline $\mathrm{DZF}$ & 194 & 0.57 & 0.09 & 198 & 0.63 & 0.08 & 188 & 0.77 & 0.07 & 152 & 0.54 & 0.12 \\
\hline DZM & 67 & 0.53 & 0.17 & 69 & 0.57 & 0.15 & 98 & 0.77 & 0.09 & 103 & 0.49 & 0.16 \\
\hline DZO & 182 & 0.60 & 0.09 & 193 & 0.74 & 0.07 & 245 & 0.71 & 0.07 & 249 & 0.52 & 0.09 \\
\hline
\end{tabular}

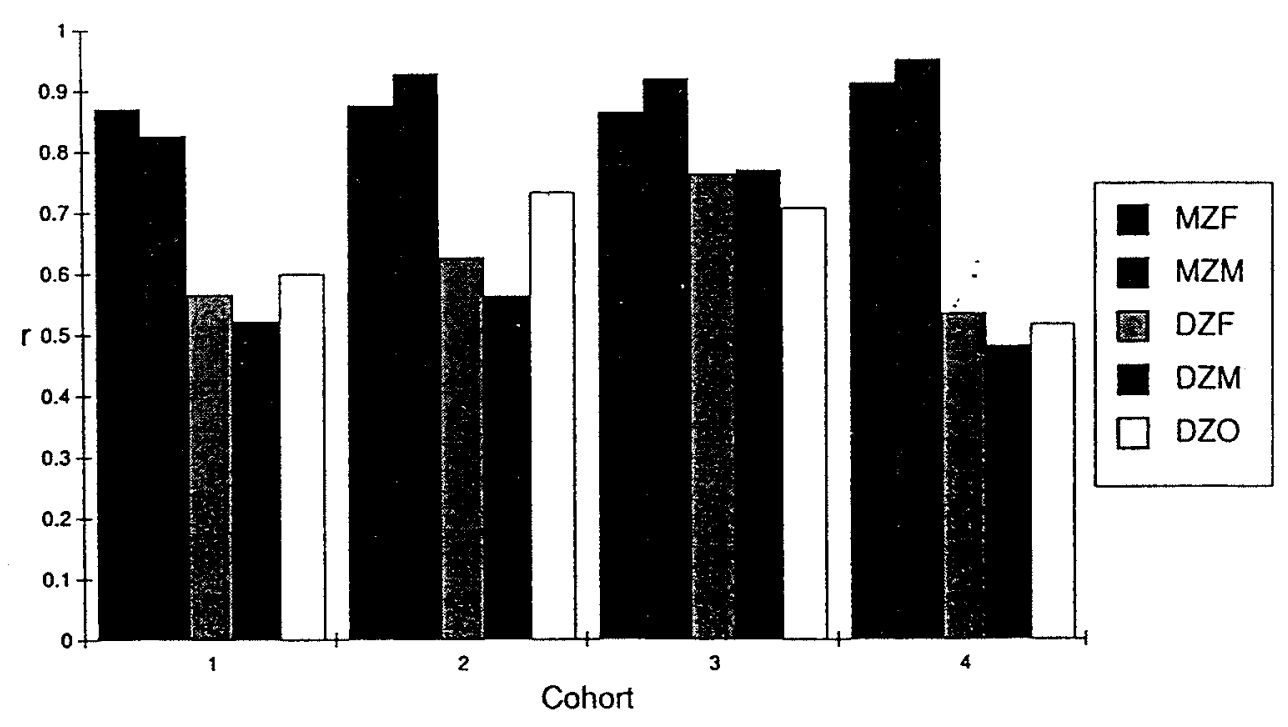

Fig. 3. Tetrachoric correlations for tonsillectomy by twin group and cohort. 
fluences to the extent $c$, and environmental influences unique to the individual to the extent $\mathrm{e}$. The correlation in additive genetic influences between twins is 1.0 for $\mathrm{MZ}$ twins and 0.5 for $\mathrm{DZ}$ twins. The expected correlations in liability of $\mathrm{MZ}$ and $\mathrm{DZ}$ twins are thus $r_{m z}=h^{2}+c^{2}$ and $r_{d z}=0.5 h^{2}+c^{2}$, while $e^{2}=1-h^{2} c^{2}$. Weighted least squares estimates of $h, c$ and $e$ were estimated from twin correlations and their asymptotic variances using LISREL 7.16 [7,9]. Results of fitting the hce model to the five twin correlations are shown for each cohort in Table 3. The fit is good for each cohort from which we can deduce that there is no significant heterogeneity in the causes of variation between males and females. Several reductions of the full model were also fitted. Dropping either $h$ or $c$ results in significant worsening of fit in the first three cohorts. In the youngest cohort, dropping $c$ from the model does not result in worsening of fit. We conclude that additive genes make significant contributions to variance in liability in all cohorts, but that shared environmental factors are only important in the first three cohorts. The proportions of variance in liability to tonsillectomy due to additive genes, shared, and individual environment in each cohort are represented in Fig. 4.

Table 3 - Results of model fitting to tonsillectomy data

\begin{tabular}{lcccccc}
\hline Model & h & c & e & df & \multicolumn{1}{l}{$\chi^{2}$} & \multicolumn{1}{c}{ p } \\
\hline Cohort 1, born before 1939 & & & & & \\
hce & 0.758 & 0.538 & 0.367 & 3 & 0.59 & 0.899 \\
h e & 0.938 & & 0.345 & 4 & 6.31 & 0.177 \\
ce & & 0.901 & 0.433 & 4 & 19.98 & 0.001 \\
e & & & 1.000 & 5 & 1047.71 & 0.000 \\
Cohort 2, born 1939-50 & & & & & \\
hce & 0.674 & 0.672 & 0.306 & 3 & 3.16 & 0.367 \\
h e & 0.964 & & 0.267 & 4 & 24.20 & 0.000 \\
ce & & 0.932 & 0.363 & 4 & 21.70 & 0.000 \\
e & & & 1.000 & 5 & 1937.16 & 0.000 \\
Cohort 3, born & $1951-58$ & & & & & \\
hce & 0.545 & 0.773 & 0.324 & 3 & 1.75 & 0.627 \\
h e & 0.959 & & 0.284 & 4 & 26.41 & 0.000 \\
ce & & 0.925 & 0.379 & 4 & 11.34 & 0.023 \\
e & & & 1.000 & 5 & 1675.50 & 0.000 \\
Cohort 4, born & $1959-64$ & & & & & \\
hce & 0.916 & 0.316 & 0.247 & 3 & 0.93 & 0.818 \\
h e & 0.970 & & 0.243 & 4 & 1.51 & 0.825 \\
ce & & 0.949 & 0.314 & 4 & 38.74 & 0.000 \\
e & & 1.000 & 5 & 2177.99 & 0.000 \\
\hline & & & & & & \\
\hline
\end{tabular}




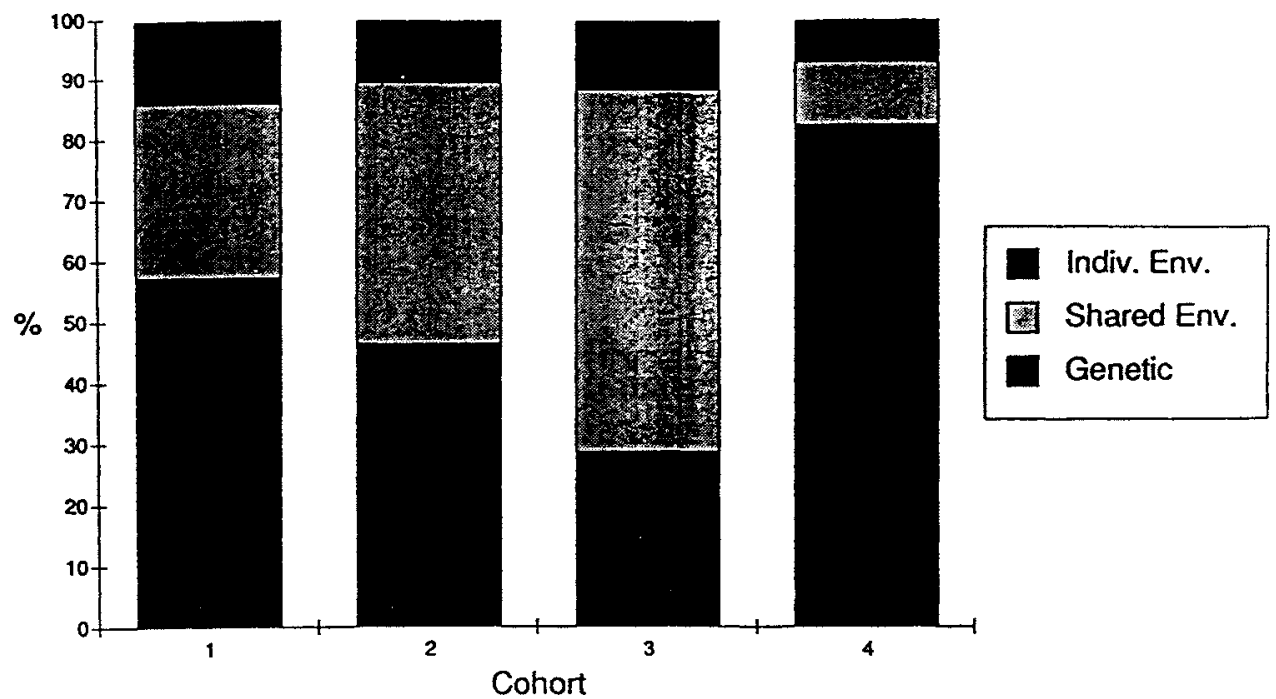

Fig. 4. Genetic, shared and individual environmental variance components for liability to tonsillectomy by cohort.

A formal test of heterogeneity of the fit of the hce model over all four birth cohorts yields $\chi_{9}^{2}=16.04(P=0.07)$. Further analysis shows that the fit to the first three cohorts is homogeneous $\left(\chi_{6}^{2}=6.90\right)$. If the data from those cohorts are pooled, the hce model gives a fit of $\chi_{1}^{2}=1.33$ and estimates of $h=0.659, c=0.672$ and $e=0.340$. Fitting the hce model jointly to the youngest cohort and the pooled data from the first three cohorts reveals tha the source of heterogeneity is between these two groups $\left(x_{3}^{2}=9.03\right.$, $\mathrm{p}=0.03$ ).

Finally, for the twins concordant for having had their tonsils out, it is of interest to examine the correlation in the age at which they had the operation, and these are shown in Table 4.

Table 4 - Correlations for age at tonsillectomy in pairs concordant for the operation

\begin{tabular}{lrc}
\hline & $\mathrm{N}$ & $\mathrm{r}$ \\
\hline MZ females & 349 & 0.676 \\
MZ males & 161 & 0.510 \\
DZ females & 156 & 0.489 \\
DZ males & 59 & 0.237 \\
DZ f-m & 181 & 0.333 \\
\hline
\end{tabular}




\section{DISCUSSION}

Our results suggest the importance of genetic factors in liability to tonsillectomy. They also illustrate, once again [6,14], that heritability is not a constant but depends on the precise characteristics of the population and the time at which it is studied. There are large differences between cohorts in the proportions of variance in liability attributable to additive genetic factors and environmental influences shared by cotwins. This latter component of variance may be caused by differing exposure to pathogens from one twin pair to another. But given the ubiquity of streptococcal bacteria [1], it is more likely to reflect differences of opinion between family doctors as to the desirability of tonsillectomy, and differences between sets of parents in their willingness to accept this advice. In the 1950 s, when many family doctors favoured tonsillectomy, shared environment accounted for $60 \%$ of variance and genetic factors for only $29 \%$. However, by the early 1960 s, when antibiotics were freely available and doctors were restricting tonsillectomy to more severe cases, heritability was up to 0.82 and family environment accounted for only $11 \%$ of variance. Environmental influences unique to the individual and not shared with cotwins account for a fairly minor proportion of the variance in liability for all cohorts, declining from $14 \%$ of the total in the oldest to $7 \%$ in the youngest.

It might be argued that the twin design is inappropriate to investigate the genetics of liability to tonsillectomy. This operation is often not perceived as being very serious, certainly not as serious as appendicectomy [3], and therefore parents (and doctors) may have a tendency to treat $\mathrm{MZ}$ twins more similarly than their $\mathrm{DZ}$ counterparts for reasons that are not always strictly medical. One can imagine that in some instances, when the decision was made to remove the tonsils of one twin, then the other twin also had tonsillectomy for prophylaxis, to keep the first twin company, or to fulfil other notions of equality. If this happened more often in MZ pairs, then one might expect the frequency of tonsillectomy to be higher in $\mathrm{MZ}$ than $\mathrm{DZ}$ twins. In fact, there is a higher rate of tonsillectomy in $\mathrm{MZ}$ twins in two of the eight groups in our sample (females in the oldest cohort and males in the youngest), but the excess is only slight.

Another manifestation of more similar treatment of $\mathrm{MZ}$ pairs might be that they more often had their tonsils out at the same time. Indeed, we do observe a higher $\mathrm{MZ}$ correlation for age at tonsillectomy in those pairs concordant for the operation (Table 4). However, this would also occur if there were genes not only influencing liability to tonsillectomy, but also the age of onset of symptoms which precipitate tonsillectomy. The relationship of the genetics of liability to the genetics of age of onset is a difficult one [12] which is beyond the scope of this paper.

Acknowledgement: The Australian Twin Registry is supported by the National Health and Medical Research Council. 


\section{REFERENCES}

1. Brook I (1987): The clinical microbiology of Waldeyer's ring. Otolaryngol Clin North Am 20:259-72.

2. Clark P, Jardine R, Jones P, Martin NG, Walsh RJ (1981): Directional dominance for low IgM and IgA levels. Am $J$ Hum Genet 33:709-21.

3. Duffy DL, Martin NG, Mathews JD (1990): Appendectomy in Australian twins. Am J Hum Genet 47:590-592.

4. Falconer DS (1965): The inheritance of liability to certain diseases estimated from the incidence among relatives. Ann Hum Genet 29:51-76.

5. Freeman JL, Jekel JF, Freeman DH (1982): Changes in age and sex specific tonsillectomy rates: United States, 1970-1977. Am J Pub Health 72:488-90.

6. Heath AC, Berg K, Eaves LJ, Solaas MH, Corey LA, Sundet J, Magnus P, Nance WE (1985): Education policy and the heritability of educational attainment. Nature 314:734-6.

7. Heath AC, Neale MC, Hewitt JK, Eaves LJ, Fulker DW (1989): Testing structural equation models for twin data using LISREL. Behav Genet 19:9-35.

8. Jöreskog KG, Sörbom D (1986): PRELIS. A Program for Multivariate Data Screening and Data Summarisation. A Preprocessor for LISREL. Mooresville, Indiana: Scientific Software Inc.

9. Jöreskog KG, Sörbom D (1989): LISREL 7. A Guide to the Program and Applications (2nd Ed). Chicago: SPSS Inc.

10. Kornblut AD (1987): A traditional approach to surgery of the tonsils and adenoids. Otolaryngol Clin North Am 20:349-61.

11: Learoyd B (1985): "Discretionary" surgery statistics. Med J Aust 142:528.

12. Neale MC, Eaves LJ, Hewitt JK, MacLean CJ, Meyer JM, Kendler KS (1989): Analyzing the relationship between age at onset and risk to relatives. Am J Hum Genet 45:226-239.

13. Richtsmeier WJ, Shikani AH (1987): The physiology and immunology of the pharyngeal lymphoid tissue. Otolaryngol Clin North Am 20:219-28.

14. Treloar SA, Martin NG (1990): Age at menarche as a fitness trait: nonadditive genetic variance detected in a large twin sample. Am J Hum Genet 47:137-148.

15. Wilson JMG (1981): Adenotonsillectomy: Scotland is beating England and Wales. Lancet i:895-90.

Correspondence: Dr. N.G. Martin, Queensland Institute of Medical Research, Bramston Terrace, Herston QLD 4006, Australia. 